02

\title{
Исследование оптических свойств комплексов квантовая точка CdZnSe/ZnS-наночастица Au
}

\author{
(ㄱ Д.А. Волгина ${ }^{1}$, Е.А. Степаниденко ${ }^{1}$, Т.К. Кормилина ${ }^{1}$, С.А. Черевков ${ }^{1}$, А. Дубовик ${ }^{1}$, \\ М.А. Баранов ${ }^{1}$, А.П. Литвин ${ }^{1}$, А.В. Федоров ${ }^{1}$, А.В. Баранов ${ }^{1}$, K. Takai ${ }^{2}$, \\ П.С. Самохвалов ${ }^{3}$, И.Р. Набиев ${ }^{3}$, Е.В. Ушакова ${ }^{1, \text { ॠ }}$ \\ ${ }^{1}$ Университет ИТМО, \\ 197101 Санкт-Петербург, Россия \\ ${ }^{2}$ Hosei University, 3-7-2 Kajino, Koganei, \\ 1848584 Tokyo, Japan \\ ${ }^{3}$ Национальный исследовательский ядерный университет „МИФИ“, Лаборатория нано-биоинженерии, \\ 115409 Москва, Россия \\ ฯ e-mail: el.ushakova@gmail.com
}

Поступила в редакцию 25.11.2017 г.

Исследовано взаимодействие золотых наночастиц (Au HЧ) и полупроводниковых квантовых точек (КТ) $\mathrm{CdZnSe} / \mathrm{ZnS}$ градиентного состава в коллоидных растворах. Показано, что интенсивность фотолюминесценции КТ в смеси уменьшается по сравнению с их исходным раствором, что обусловлено резонансным безызлучательным переносом энергии от КТ к Аu НЧ в спонтанно образовавшихся агрегатах. Для управляемого образования пар взаимодействующих КТ и Аu НЧ нами предложена методика создания комплексов КТ-Аи НЧ, связанных специальными молекулами-лигандами. Показано, что морфология и оптические свойства полученных образцов зависят от способа их приготовления, в частности, химического окружения КТ. Показано, что комплексы образуются при добавлении гидрофильной фазы Аu НЧ в гидрофобную фазу КТ, при этом оптические свойства последних практически не изменяются по сравнению с квазиизолированными КТ в коллоидном растворе.

DOI: $10.21883 /$ OS.2018.04.45747.272-17

\section{Введение}

Одним из направлений современного материаловедения является создание гибридных материалов на основе наноразмерных объектов, обладающих уникальными физическими и химическими свойствами. Благодаря стремительному развитию методик синтеза наноструктурированных материалов в последнее десятилетие стало возможным создавать наночастицы различной формы, размеров и химического состава с уникальными оптическими откликами [1-8]. Сочетание таких уникальных свойств открывает возможность создания материалов с заданным набором параметров, необходимым для их дальнейшего применения. Так, были созданы новые гибридные многокомпонентные материалы на основе систем взаимодействующих нанообъектов: ансамблей КТ [9-11], комплексов НЧ с графеном [12,13], комплексов магнитных НЧ с КТ [14,15], диэлектрических НЧ $[16,17]$, металлических НЧ и КТ [18-21] и других.

Гибридные комплексы на основе металлических наночастиц (НЧ) и полупроводниковых квантовых точек (КТ) привлекают особый интерес, так как в них уникальные оптические свойства КТ, такие как высокий квантовый выход фотолюминесценции и большие значения коэффициентов экстинкции в широком спектральном диапазоне, усилены за счет локальных полей вблизи металлических НЧ. Такие материалы являются перспективными для их применения в устройствах фотоники: солнечных элементах и элементах для фотоката- лиза [22]. Другой областью потенциального применения является их использование в качестве биологических сенсоров [23,24], в том числе селективного зондирования аминокислот [19]. Также гибридные комплексы КТ-НЧ могут быть применены для улучшения визуализации биологических тканей с помощью оптической микроскопии $[25,26]$. Таким образом, разработка протоколов образования гибридных комплексов КТ-НЧ в коллоидном растворе с управляемыми морфологическими параметрами является актуальной задачей.

В настоящей работе было исследовано взаимодействие полупроводниковых аллоидных $\mathrm{CdZnSe} / \mathrm{ZnS}$ с $\mathrm{Au}$ НЧ в коллоидных растворах и изменение их оптических свойств в зависимости от морфологии образованных комплексов.

\section{Экспериментальные методы исследования}

Спектральный анализ образцов КТ и золотых НЧ в растворе и полученных комплексах на подложках проведен с использованием спектрофотометра UV-3600 (Shimadzu), спектрофлуориметра Cary Eclipse (Varian) и конфокального микроскопа LSM-710 (Zeiss). Для изучения морфологии сформированных комплексов был использован электронный микроскоп Merlin (Zeiss). Люминесцентные изображения, а также микрофотографии образцов в проходящем свете были получены с исполь- 

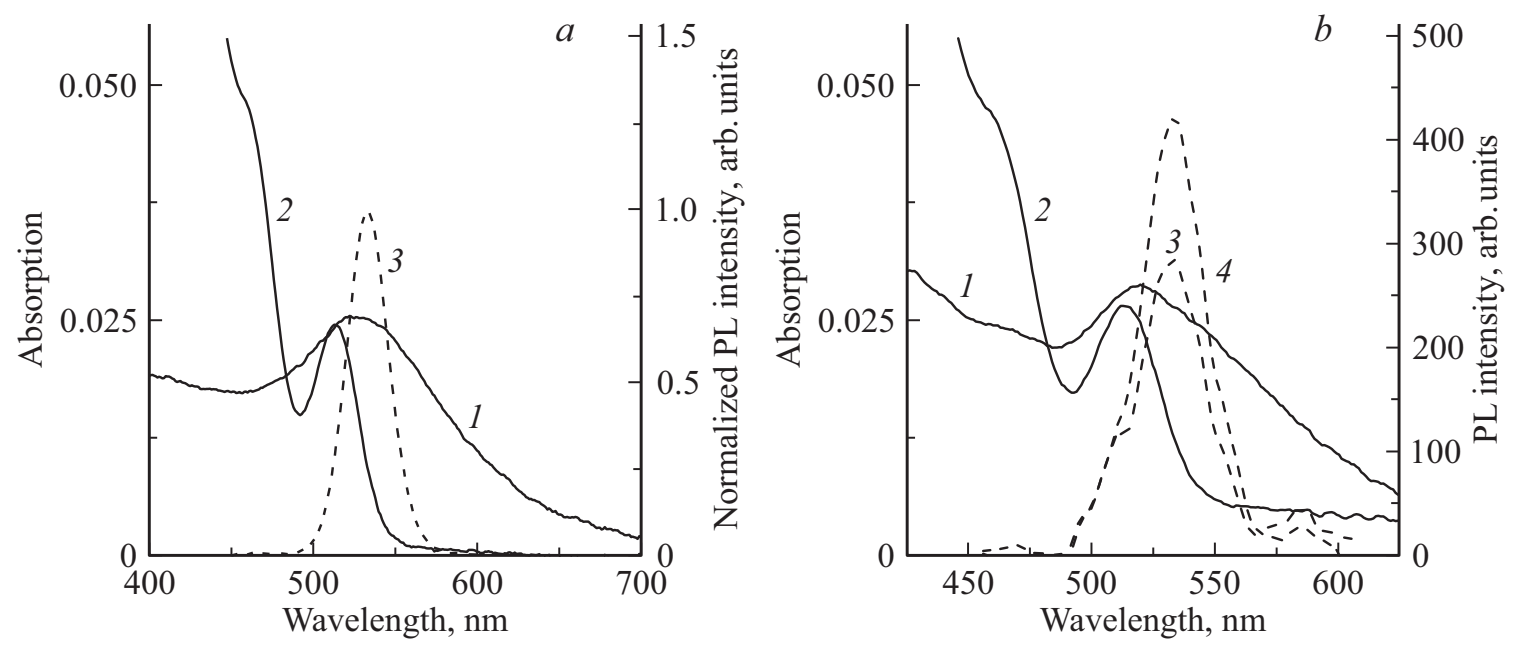

Рис. 1. (a) Спектры поглощения (сплошные линии) и ФЛ (штриховая линия) исходных коллоидных растворов: $1-$ Аи НЧ, 2 и 3 - КТ; $(b)$ спектры поглощения (сплошные линии) и ФЛ (штриховые линии) смеси растворов при максимальной величине добавки второй компоненты: 1 и $3-$ рНЧ + КТ, 2 и $4-$ рКТ + НЧ.

зованием конфокального микроскопа LSM-710 (Zeiss). Исследование кинетики затухания фотолюминесценции (ФЛ) проведен с использованием конфокального микроскопа MicroTime100 (PicoQuant), в котором реализован метод время-коррелированного счета одиночных фотонов.

\section{Материалы}

В работе нами были использованы коллоидные КТ градиентного состава $\mathrm{CdZnSe} / \mathrm{ZnS}$. Они были получены методом органо-металлического синтеза в органическом растворе по методике, описанной в работе [27]. В результате синтеза были получены КТ с диаметром $7.0 \pm 1.0 \mathrm{~nm}$, стабилизированные органическими молекулами-лигандами - триоктилфосфин оксида (trioctylphosphine oxide, ТОРО) и олеиновой кислоты (oleic acid, OA) с длиной цепочек 1.3 и $1.8 \mathrm{~nm}$ соответственно. Коллоидные наночастицы золота (Аu HЧ) были синтезированы по методике, описанной в работе [28]. В результате синтеза были получены НЧ с размером $6.0 \pm-0.8 \mathrm{~nm}$, стабилизированные молекулами полиэтиленгликоля (polyethylene glycol, PEG) с длиной цепочки $3.5 \mathrm{~nm}$. Спектры поглощения и ФЛ коллоидных растворов нанокристаллов в органических растворителях представлены на рис. $1, a$.

Для исследования взаимодействия квазиизолированных коллоидных нанокристаллов с исходными молекулами-лигандами в органическом растворителе были приготовлены две серии образцов. В ходе приготовления первой серии, обозначенной далее в тексте как pКТ + НЧ, к раствору КТ добавлялся раствор Аи НЧ по $10 \mu 1$, максимальная величина добавки составила $100 \mu 1$. В ходе приготовления второй серии, обозначенной далее в тексте как $\mathrm{pH}+\mathrm{KT}$, наоборот, в раствор Аu НЧ добавлялся раствор КТ. При каждом добавлении реги- стрировались спектры поглощения и ФЛ. На рис. $1, b$ представлены зарегистрированные спектры поглощения и ФЛ двух растворов смеси при максимальной величине добавки. Видно, что в обоих случаях полоса ФЛ остается практически неизменной, изменяется лишь ее интенсивность. Для серии $\mathrm{pHЧ}+$ КТ она линейно увеличивается, a для серии рКТ + НЧ уменьшается.

Для того чтобы понять, происходит ли взаимодействие КТ и Аu НЧ в смеси растворов, было проведено сравнение экспериментальных значений интегральной интенсивности ФЛ $\left(S(P L)_{\text {exp }}\right)$ с рассчитанными $\left(S(P L)_{\text {calc }}\right)$ в зависимости от вклада КТ в оптическую плотность смеси растворов $\left(D_{Q D}\right)$ в максимуме экситонного пика $(514 \mathrm{~nm}): S(P L)_{\text {calc }}=$ $=D_{Q D} \cdot S(P L)_{e x p}^{*} / D_{Q D \text { sol. }}$, где $S(P L)_{\text {exp }}^{*}$ и $D_{Q D \text { sol. }}$ значения интегральной интенсивности ФЛ и оптической плотности исходного раствора КТ соответственно. Величина вклада КТ в оптическую плотность смеси в случае добавления в Аu НЧ раствор КТ рассчитывалась как $D_{Q D}=D_{Q D \text { sol. }} \cdot V_{Q D \text { sol. }} / V_{\text {mix }}$, где $V_{Q D \text { sol. и }} V_{\text {mix }}-$ объем исходного раствора КТ и раствора смеси соответственно. В случае добавления КТ в раствор Аи НЧ: $D_{Q D}=D_{Q D}-D_{\mathrm{Au}} \cdot V_{\mathrm{Au}} / V_{\text {mix }}$, где $D_{\mathrm{Au}}$ и $V_{\mathrm{Au}}$ - оптическая плотность на длине волны $514 \mathrm{~nm}$ и объем раствора $\mathrm{Au}$ НЧ соответственно. Полученные зависимости в сравнении с экспериментальными данными представлены на рис. 2.

Экспериментальные значения в обоих случаях меньше теоретических, т.е. в смеси растворов в присутствии наночастиц золота происходит тушение фотолюминесценции КТ. Было оценено значение отношения теоретических значений к экспериментальным (относительный коэффициент тушения). Полученное значение относительного коэффициента тушения возрастает с уменьшением концентрации КТ в смеси. Это в основном связано с нежелательным и неконтролируемым процессом резо- 

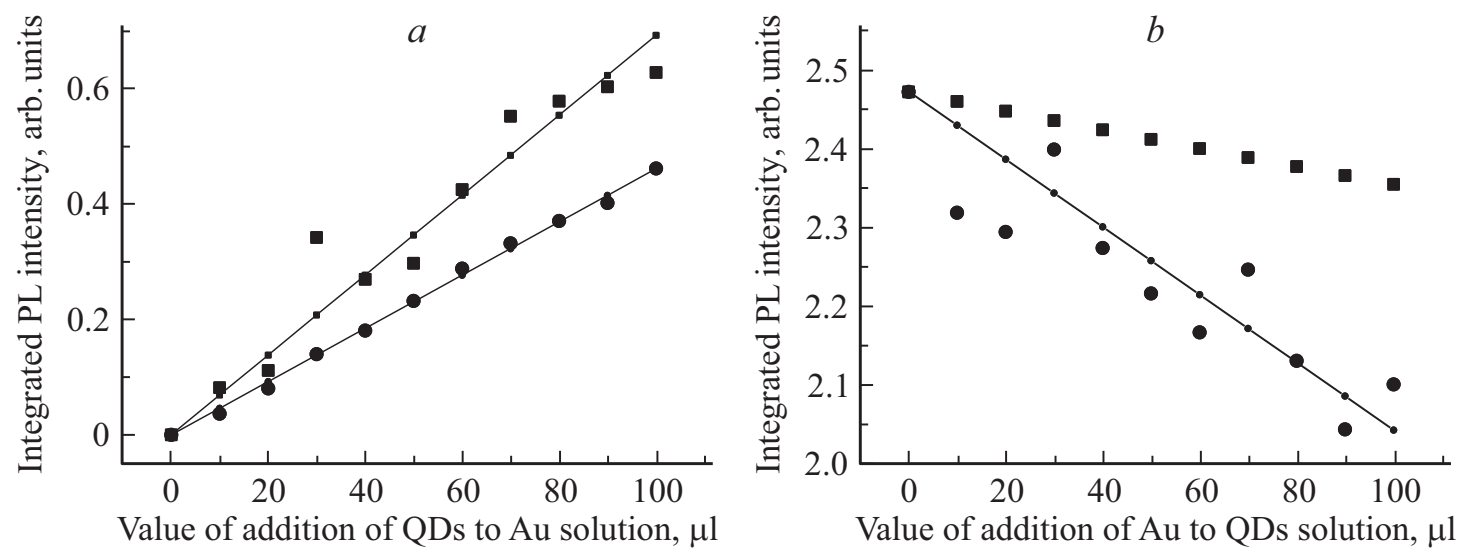

Рис. 2. Зависимости изменения интегральной интенсивности ФЛ КТ: рассчитанная (квадраты) и экспериментальная (круги) при добавлении $N \mu l$ второй компоненты: (a) pНЧ + КТ; (b) pКТ + НЧ.
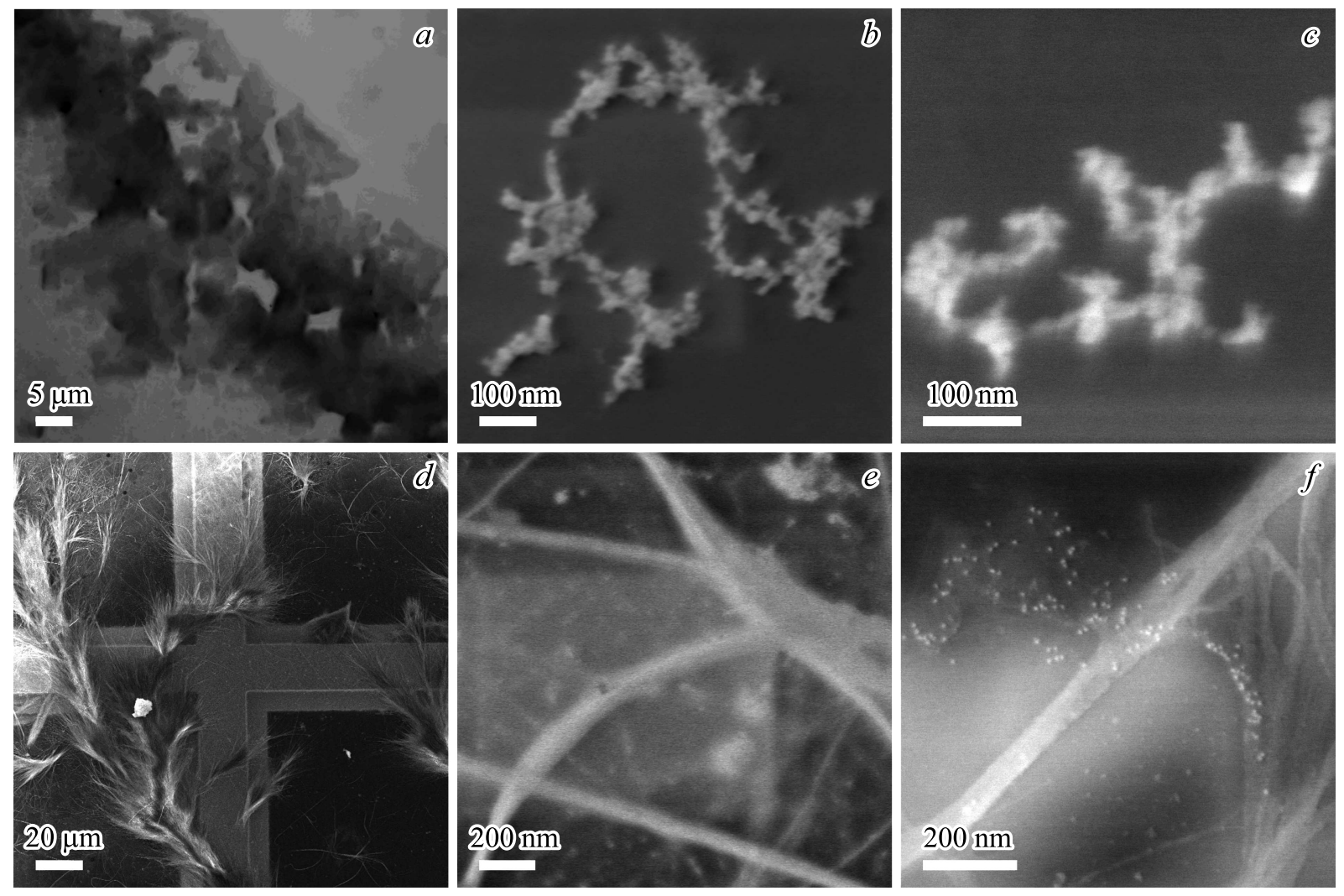

Рис. 3. (a) Микроизображение образца сравнения на стеклянной подложке в проходящем свете; $(b)-(f)$ : изображения образцов $1(b), 2(c), 3(d, e)$ и $4(f)$, полученные методом сканирующей электронной микроскопии (СЭМ).

нансного переноса энергии от КТ на Аи НЧ в спонтанно образовавшихся агрегатах в смеси растворов. В связи с этим перед нами встала задача создания комплексов КТ-НЧ, связанных органической молекулой-лигандом с контролируемым расстоянием между нанокристаллами в коллоидном растворе.

Для того чтобы получить коллоидные комплексы $\mathrm{Au}$ НЧ и КТ были необходимы органические молекулы, обладающие двумя активными группами: тиольной
$(-\mathrm{SH})$ и карбоксильной $(-\mathrm{COOH})$, которые ковалентно связываются с атомами $\mathrm{Au}$ и $\mathrm{Zn}$ на поверхности НЧ и КТ соответственно. Для этого были выбраны молекулы: 4-меркаптобензойной кислоты (4-mercaptobenzoic acid, 4MBA) и 6-меркаптогексановой кислоты (6-mercaptohexanoic acid, 6MHA). Сначала была проведена процедура солюбилизации Аu НЧ выбранными молекулами по методике, схожей с описанной в работе [29]. После солюбилизации НЧ диспергировались в водном растворе 
Таблица 1. Название и химический состав образцов растворов

\begin{tabular}{l|c|c|c|c|c}
\hline $\begin{array}{c}\text { Название } \\
\text { образца }\end{array}$ & $\begin{array}{c}\text { Образец } \\
\text { сравнения }\end{array}$ & 1 & 2 & 3 & 4 \\
\hline Растворитель & Толуол & ТСМ & ТСМ & $\mathrm{H}_{2} \mathrm{O}$ & $\mathrm{H}_{2} \mathrm{O}$ \\
\hline Тип КТ лиганда & TОРО + ОА & - & - & - & - \\
\hline $\begin{array}{l}\text { Тип Аи НЧ } \\
\text { лиганда }\end{array}$ & PЕG & 4МВА & 6МНА & 4МВА & 6МНА
\end{tabular}

с добавлением $\mathrm{NaOH}$. Для лучшего связывания выбранных лигандов с КТ их поверхность предварительно была очищена от исходных молекул-лигандов, ТОРО и ОА.

В первой серии образцов $50 \mu 1$ водного раствора НЧ добавлялось в $450 \mu 1$ раствора КТ в тетрахлорметане (tetrachloromethane, ТCM). Во второй серии образцов $50 \mu 1$ раствора КТ в ТСМ добавлялось в $450 \mu 1$ водного раствора НЧ. Для наглядности названия образцов, тип растворителя и молекул на поверхности КТ и Аu НЧ сведены в табл. 1.

Изображения с электронного микроскопа образцов, полученных нанесением малого количества растворов смесей на сеточки для электронной микроскопии, приведены на рис. 3. Также на рис. 3, а приведено микроизображение образца, полученного нанесением на стеклянную подложку раствора образца сравнения.

Видно, что при нанесении раствора смеси образца сравнения на стеклянную подложку образуются разупорядоченные структуры, в которых нанокристаллы образуют большие агрегаты. При нанесении на сеточки растворов образцов 1 и 2 наблюдается образование цепочек, состоящих из элементов порядка $10 \mathrm{~nm}$ (рис. 3, $b, c$ ). Это свидетельствует о связывании Аu НЧ и КТ в коллоидном растворе и их осаждении в таком виде. В случае образцов 3 и 4 наблюдается образование больших нитеподобных структур из органических молекул, типичное СЭМ изображение которых приведено на рис. 3, $d$. При этом нанокристаллы хаотически распределены по площади этих нитеподобных структур (рис. $3, e, f)$. Следовательно, в этих образцах связывания Аu НЧ и КТ в комплексы не произошло.

\section{Результаты и обсуждение}

Были получены микроизображения образцов, образованных нанесением полученных растворов на стеклянную подложку. На рис. 4 представлены типичные люминесцентные изображения.

Анализ оптических микрофотографий показал, что в первой серии образуются маленькие сферы с размерами около $10-30 \mu \mathrm{m}$. В образце 1 КТ в основном находятся в сферах, которые расположены на подложке обособленно. В образце 2 также наблюдалась структура со сферическими объектами, больше похожими на мицеллы. В этом случае КТ распределены по границе мицелл. По сравнению с исходными растворами для первого и второго образцов происходит незначительный сдвиг полос ФЛ в коротковолновую область соответственно на 4 и $8 \mathrm{~nm}$. На микроизображениях второй серии видно, что при нанесении растворов на подложку образуются нитевидные структуры (рис. 4,e,f), что согласуется с полученными СЭМ изображениями, где подложкой являлись сеточки для электронной микроскопии. При этом КТ не встраиваются в структуры, образованные органическими молекулами. Для образцов 3 и 4 наблюдается уменьшение интенсивности ФЛ вместе с незначительным сдвигом полосы ФЛ в коротковолновую область. Положение полос ФЛ для образцов приведено в табл. 2.

Для установления влияния нахождения $\mathrm{Au}$ НЧ вблизи КТ, а также способа приготовления комплексов и химического окружения КТ на их оптические свойства, были проведены исследования кинетических параметров ФЛ. Были получены карты времен затухания и интенсивности ФЛ образцов. При этом кривая затухания ФЛ представляла собой сумму люминесцентных откликов, регистрируемых в каждой точке, по записанной области. Анализ кинетики ФЛ образцов показал, что кривые затухания ФЛ можно описать экспоненциальной зависимостью вида: $I(t)=\sum_{i} A_{i} \cdot e^{-i / \tau}$. Среднее время затухания люминесценции вычислялось по формуле: $\langle\tau\rangle=\frac{\Sigma A_{i} \tau_{i}^{2}}{\Sigma A_{i} \tau_{i}}$. На рис. 5 приведены типичные кривые затухания люминесценции образцов.

Сначала были исследованы оптические отклики образца сравнения. В образце $\mathrm{pHЧ} \mathrm{+} \mathrm{КТ} \mathrm{время} \mathrm{затухания} \mathrm{ФЛ}$ КТ составляет $14.8 \pm 1.2 \mathrm{~ns}$, а в случае рКТ $+\mathrm{HЧ} \mathrm{-}$ $11.9 \pm 0.9 \mathrm{~ns}$. Для того чтобы понять, каким образом расположены КТ в агрегатах с Аu НЧ, были получены

Таблица 2. Спектральные характеристики образцов в сравнении с исходным коллоидным раствором КТ

\begin{tabular}{l|c|c|c|c|c|c}
\hline \multicolumn{1}{c|}{ Название образца } & Образец сравнения & 1 & 2 & 3 & 4 & Исходный раствор КТ \\
\hline Морфология & Агрегаты & \multicolumn{2}{|c|}{$\begin{array}{c}\text { Связанные } \\
\text { комплексы }\end{array}$} & \multicolumn{2}{|c|}{$\begin{array}{c}\text { Разупорядоченные } \\
\text { ансамбли }\end{array}$} & $\begin{array}{c}\text { Квази- } \\
\text { изолированные }\end{array}$ \\
\hline Пик ФЛ, nm & 533 & 530 & 526 & 528 & 529 & 534 \\
\hline Интенсивность ФЛ, arb.units. & 10 & 450 & 350 & 100 & 10 & - \\
\hline Время затухания ФЛ КТ, ns & $13.1 \pm 1.5$ & $25.5 \pm 1.5$ & $27.7 \pm 0.8$ & $26.3 \pm 1.0$ & $16.0 \pm 5.5$ & $36.0 \pm 2.0$
\end{tabular}



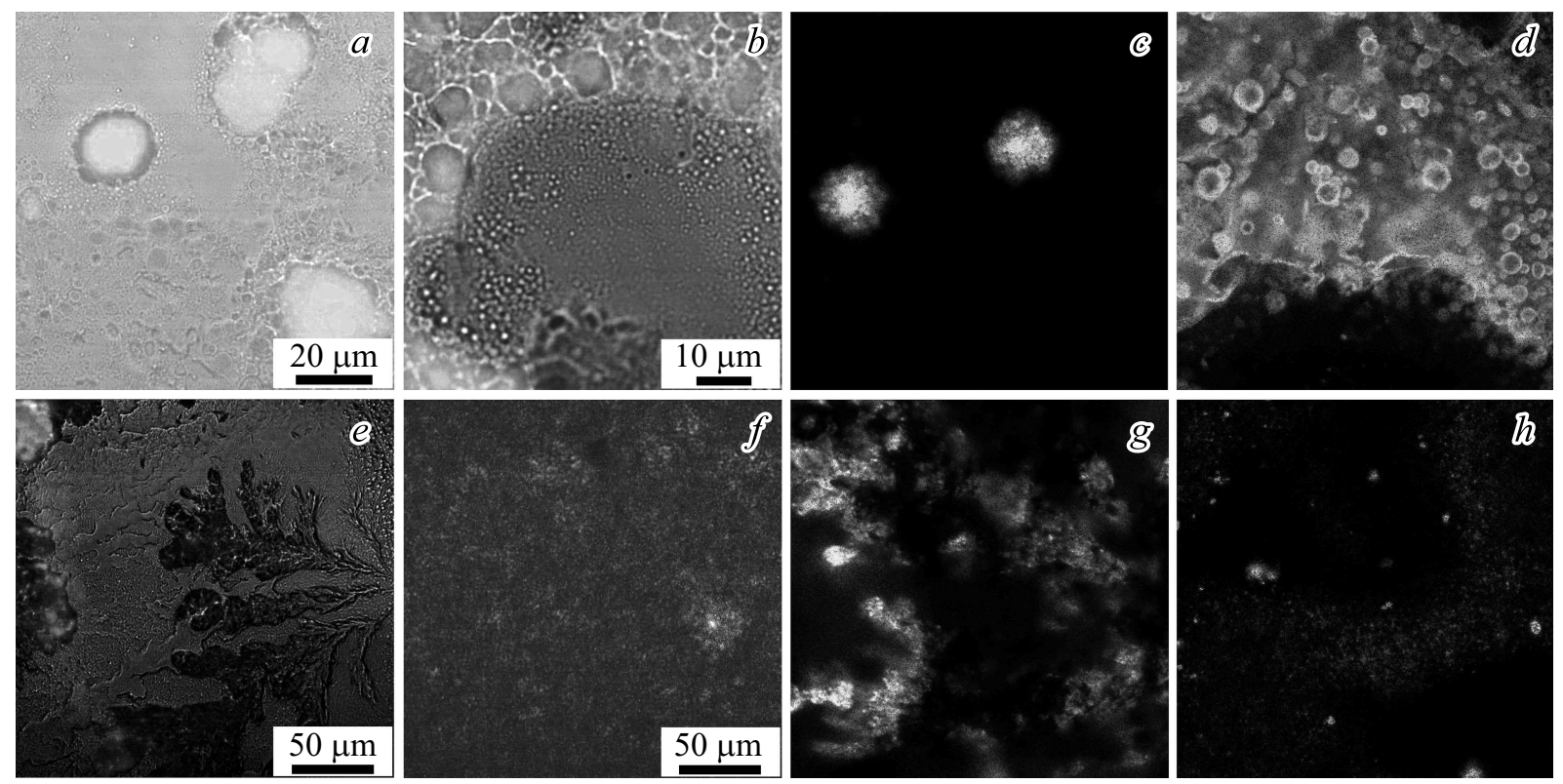

Рис. 4. $(a),(b),(e),(f)$ - люминесцентные микроизображения, совмещенные с микроизображениями в проходящем свете; $(c)$, $(d),(g),(h)$ - карты времен затухания ФЛ $80 \times 80 \mu$ т образцов: $1-(a)$ и $(c), 2-(b)$ и $(d), 3-(e)$ и $(g), 4-(f)$ и $(h)$.
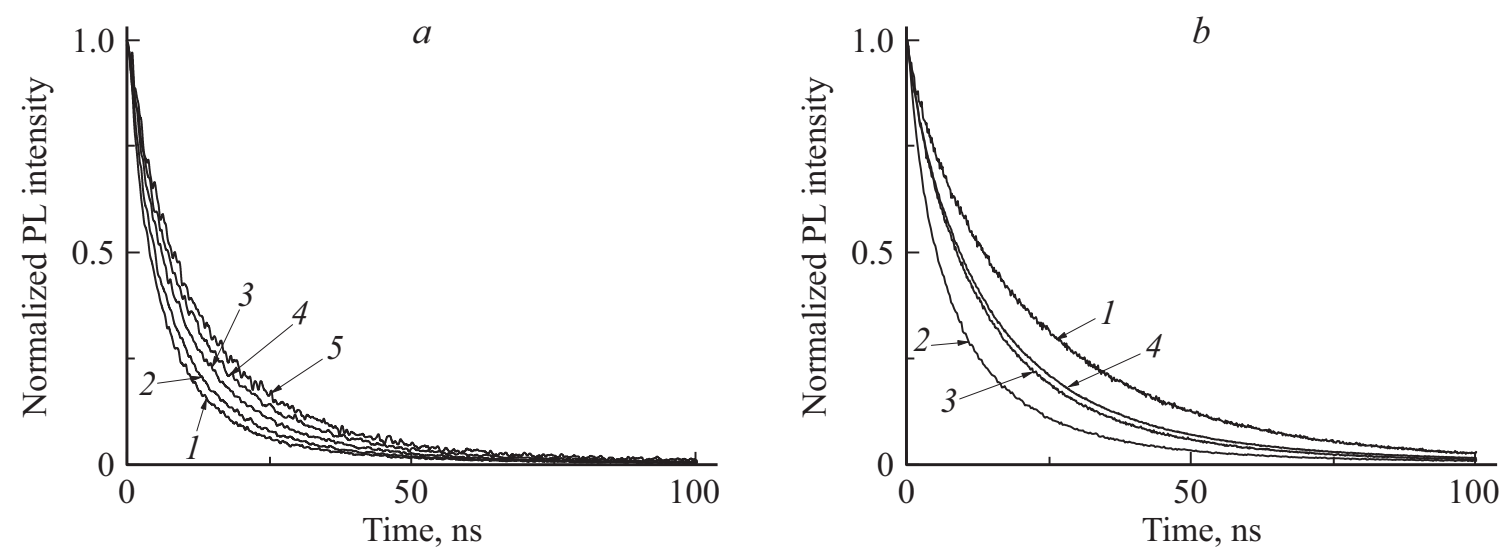

Рис. 5. Нормированные кривые затухания ФЛ: $(a)$ для образца рКТ + НЧ при различных длинах волн регистрации излучения: $1-520,2-530,3-540,4-550,5-560 \mathrm{~nm} ;(b)$ для образцов: 1 - исходный раствор КТ, $2-$ рКТ + НЧ, $3-$ образец 1 , 4 - образец 3.

кривые затухания ФЛ КТ при различных длинах волн регистрации в диапазоне 520-560 nm с использованием интерференционных фильтров. Полученные зависимости представлены на рис. 5, $a$. Оказалось, что для длины волны $520 \mathrm{~nm}$ среднее время затухания составляло $8.4 \mathrm{~ns}$, а для $560 \mathrm{~nm}-16.8 \mathrm{~ns}$. Полученные зависимости говорят о том, что уменьшение времени затухания ФЛ не вызвано взаимодействием с $\mathrm{Au} \mathrm{HЧ} \mathrm{и,} \mathrm{вероятнее}$ всего, вызвано образованием агрегатов КТ. В таком случае может происходить безызлучательный перенос энергии от КТ меньшего размера к большим внутри квазимонодисперсного ансамбля КТ в агрегатах.

На рис. 5, $b$ приведены типичные кривые затухания ФЛ для образцов 1 и 3 в сравнении с исходными коллоидными растворами КТ, а также образцом сравнения.
Видно, что значения средних времен затухания ФЛ КТ в образцах обеих серий немного ниже значений для исходного раствора, но больше значений, наблюдаемых для образца сравнения. Средние значения времен затухания ФЛ, полученные в результате аппроксимации интенсивности ФЛ для всех образцов, приведены в табл. 2. Усреднение значений проводилось по нескольким записываемым областям в каждом образце.

Для первой серии образцов наблюдалось незначительное уменьшение времен затухания ФЛ КТ, средние значения которого составили $25.5 \pm 1.5$ и $27.7 \pm 0.8 \mathrm{~ns}$ для образцов 1 и 2 соответственно. Как видно на рис. 4, $c, d$, структуры, образованные комплексами КТ и $\mathrm{Au} \mathrm{HЧ,}$ обладают примерно одинаковыми параметрами ФЛ, как интенсивностью, так и значением времен затухания. 
Это свидетельствует об однородном распределении КТ и $\mathrm{Au}$ НЧ в структурах, что также косвенно является подтверждением образования связанных комплексов в этих образцах.

В отличие от первой серии образцов для второй серии наблюдалось пространственное распределение параметров ФЛ КТ в зависимости от морфологии образца. На рис. $4, g, h$ видны отдельные области, обладающие меньшими значениями времен затухания ФЛ и большей относительной интенсивностью. Однако данные ярко люминесцирующие области вносили малый вклад в общий сигнал кинетики затухания ФЛ, суммируемый по всей записываемой области образца. Для образца 3 среднее время затухания ФЛ составило $26.3 \pm 1.0 \mathrm{~ns}$. Для образца 4 наблюдалось сильное уменьшение интенсивности ФЛ, которое сопровождалось уменьшением значения среднего времени затухания до значений $16.0 \pm 5.5 \mathrm{~ns}$. Мы предполагаем, что данное изменение оптических свойств КТ во второй серии образцов связано с методикой приготовления комплексов, при которой связывание КТ и Аu НЧ практически не происходит. Следовательно, карбоксильные группы выбранных молекул-лигандов не связываются с поверхностью КТ взамен исходных молекул ТОРО и ОА, что приводит к образованию дополнительных каналов безызлучательной релаксации энергии фотовозбуждения.

\section{Заключение}

В работе исследовано взаимодействие золотых наночастиц и полупроводниковых КТ градиентного состава в коллоидных растворах. Показано, что интенсивность фотолюминесценции КТ в смеси уменьшается по сравнению с их исходным раствором. Это обусловлено резонансным безызлучательным переносом энергии от КТ к наночастицам при их близком расположении в спонтанно образовавшихся агрегатах в смеси. Для управления процессом создания пар КТ-наночастица нами была предложена методика создания комплексов КТ-золотая наночастица, связанных специальными молекулами-лигандами, в коллоидном растворе. Показано, что морфология и оптические свойства полученных образцов зависят от способа их приготовления, в частности, химического окружения КТ. Показано, что комплексы образуются при добавлении гидрофильной фазы наночастиц золота в гидрофобную фазу КТ, при этом оптические свойства практически остаются неизменными по сравнению с квазиизолированными КТ в коллоидном растворе. Для получения усиления оптических сигналов КТ в таких комплексах необходимы дальнейшие исследования по оптимизации методик приготовления систем с контролируемыми морфологическими параметрами комплексов КТ-наночастица.

Полученные в работе результаты расширят понимание взаимодействия компонент в гибридных наноструктури- рованных материалах для их дальнейшего успешного применения в устройствах нанооптики и фотоники.

Авторы благодарят Минобрнауки РФ (грант МК-1757.2017.2, грант 14.В25.31.0002) за финансовую поддержку работы.

\section{Список литературы}

[1] Kagan C.R., Lifshitz E., Sargent E.H., Talapin D.V. // Science. 2016. V. 353. N 6302. P. aac5523.

[2] Talapin D.V., Shevchenko E.V. // Chem. Rev. 2016. V. 116. N 18. P. 10343-10345.

[3] Neretina S., Hughes R.A., Gilroy K.D., Hajfathalian M. // Acc. Chem. Res. 2016. V. 49. N 10. P. 2243-2250.

[4] Owen J., Brus L. // J. Amer. Chem. Soc. 2017. V. 139. N 32. P. 10939-10943.

[5] Susumu K., Field L.D., Oh E., Hunt M., Delehanty J.B., Palomo V., Dawson P.E., Huston A.L., Medintz I.L. // Chem. Mater. 2017. V. 29. N 17. P. 7330-7344.

[6] Hedayatnasab Z., Abnisa F,, Daud W.M.A.W. // Materials \& Design. 2017. V. 123. P. 174-196.

[7] Aslam U., Linic S. // Chem. Mater. 2016. V. 28. N 22. P. 8289-8295.

[8] Kim Y., Yeom B., Arteaga O., Yoo S.J., Lee S.G., Kim J.G., Kotov N.A. // Nat. Mater. 2016. V. 15. N 4. P. 461-468.

[9] Litvin A.P., Babaev A.A., Parfenov P.S., Ushakova E.V., Baranov M.A., Andreeva O.V., Berwick K., Fedorov A.V., Baranov A.V. // J. Phys. Chem. C. 2017. V. 121. N 15. P. $8645-8652$.

[10] Ushakova E.V., Cherevkov S.A., Litvin A.P., Parfenov P.S., Volgina D.-O.A., Kasatkin I.A., Fedorov A.V., Baranov A.V. /I J. Phys. Chem. C. 2016. V. 120. N 43. P. 25061-25067.

[11] Ushakova E.V., Cherevkov S.A., Litvin A.P., Parfenov P.S., Zakharov V.V., Dubavik A., Fedorov A.V., Baranov A.V. /I Opt. Express. 2016. N 24. P. A58-A64.

[12] Резник И.А., Громова Ю.А., Златов А.С., Баранов М.А., Орлова А.О., Мошкалев С.А., Маслов В.Г., Баранов А.В., Федоров А.В. // Опт. и спектр. 2017. Т. 122. № 1. C. 126-132; Reznik I.A., Gromova Yu.A., Zlatov A.S., Baranov M.A., Orlova A.O., Moshkalev S.A., Maslov V.G., Baranov A.V., Fedorov A.V. // Opt. Spectrosc. 2017. V. 122. N 1. P. $114-119$.

[13] Huang K.J., Niu D.J, Liu X., Wu Z.W., Fan Y., Chang Y.F,, $W u$ Y.Y. // Electrochimica Acta. 2011. V. 56. N 7. P. $2947-2953$.

[14] Visheratina A.K., Purcell-Milton F., Serrano-García R., Kuznetsova V.A., Orlova A.O., Fedorov A.V., Baranov A.V., Gun'ko Y.K. // J. Mater. Chem. C. 2017. V. 5. N 7. P. 1692-1698.

[15] Lou L., Yu K., Zhang Z., Li B., Zhu J., Wang Y., Huang R., Zhu Z. // Nanoscale. 2011. V. 3. N 5. P. 2315-2323.

[16] Tiguntseva E., Chebykin A., Ishteev A., Haroldson R., Balachandran B., Ushakova E., Komissarenko F., Wang H., Milichko V., Tsypkin A., Zuev D., Hu W., Makarov S., Zakhidov A. // Nanoscale. 2017. V. 9. N 34. P. 12486-12493.

[17] Dmitriev P.A., Baranov D.G., Milichko V.A., Makarov S.V., Mukhin I.S., Samusev A.K., Krasnok A.E., Belov P.A., Kivshar Y.S. // Nanoscale. 2016. V. 8. N 18. P. 9721-9726.

[18] Ridolfo A., Di Stefano O., Fina N., Saija R., Savasta S. /I Phys. Rev. Lett. 2010. V. 105. N 26. P. 263601. 
[19] Paramanik B., Kundu S., De G., Patra A. // J. Mater. Chem. C. 2016. V. 4. N 3. P. 486-496.

[20] Cox J.D., Singh M.R., Von Bilderling C., Bragas A.V. // Adv. Opt. Mater. 2013. V. 1. N 6. P. 460-467.

[21] Strelow C., Theuerholz T.S., Schmidtke C., Richter M., Merkl J.P., Kloust H., Ye Z., Weller H., Heinz T.F., Knorr A., Lange H. // Nano Lett. 2016. V. 16. N 8. P. 4811-4818.

[22] Chen Y.S., Choi H., Kamat P.V. // J. Am. Chem. Soc. 2013. V. 135. N 24. P. $8822-8825$.

[23] Liu J., Cui M., Zhou H., Zhang S. // Sci. Rep. 2016. V. 6. P. 30577.

[24] Pons T., Medintz I.L., Sapsford K.E., Higashiya S., Grimes A.F., English D.S., Mattoussi H. // Nano Lett. 2007. V. 7. N 10. P. 3157-3164.

[25] Resch-Genger U., Grabolle M., Cavaliere-Jaricot S., Nitschke R., Nann T. // Nat. Methods. 2008. V. 5. N 9. P. 763-775.

[26] Petryayeva E., Algar W.R., Medintz I.L. // Appl. Spectrosc. 2013. V. 67. N 3. P. 215-252.

[27] Bae W.K., Kwak J., Lim J., Lee D., Nam M.K., Char K., Lee C., Lee S. // Nano Lett. 2010. V. 10. N 7. P. 2368-2373.

[28] Dubavik A., Lesnyak V., Gaponik N., Eychmüller A. // Langmuir. 2011. V. 27. N 16. P. 10224-10227.

[29] Ушакова Е.В., Кормилина Т.К., Буркова М.А., Черевков С.А., Захаров В.В., Турков В.К., Федоров А.В., Баранов А.В. // Опт. и спектр. 2017. Т. 122. № 1. C. 31-35; Ushakova E.V., Kormilina T.K., Burkova M.A., Cherevkov S.A., Zakharov V.V., Turkov V.K., Fedorov A.V., Baranov A.V. // Opt. Spectrosc. 2017. V. 122. N 1. P. 25-29. 